\title{
Naturally clonal vertebrates are an untapped resource in ecology and evolution research
}

Kate L. Laskowski (1) http://orcid.org/0000-0003-1523-9340, Carolina Doran (1D https://orcid.org/0000-0002-7814-4675, David Bierbach 는 http://orcid.org/0000-0001-7049-2299, Jens Krause, Max Wolf

DOI

10.1038/s41559-018-0775-0

Original publication date

28 January 2019 (First Online)

Document version

Author's accepted manuscript version

Published in

Nature Ecology \& Evolution

\section{Citation}

Laskowski KL, Doran C, Bierbach D, Krause J, Wolf M. Naturally clonal vertebrates are an untapped resource in ecology and evolution research. Nature Ecology \& Evolution. 2019;3(2):161-9. 


\section{Naturally clonal vertebrates are an untapped}

\section{2 resource in ecology and evolution research}

3 Kate L. Laskowski ${ }^{1}$, Carolina Doran ${ }^{1}$, David Bierbach ${ }^{1}$, Jens Krause ${ }^{1,2}$, Max Wolf

$4 \quad{ }^{1}$ Department of Biology \& Ecology of Fishes, Leibniz-Institute of Freshwater Ecology \& Inland Fisheries,

5 Müggelseedamm 310, 12587 Berlin Germany

$6 \quad{ }^{2}$ Faculty of Life Sciences, Humboldt-Universität zu Berlin, Invalidenstrasse 42, 10115 Berlin Germany

7 Correspondence to KLL

8 e-mail: laskowski@igb-berlin.de

\section{Abstract |}

12 Science requires replication. The development of many cloned or isogenic model 13 organisms is a testament to this. But researchers are reluctant to use these traditional

14 animal model systems for certain questions in evolution or ecology research because of

15 concerns over relevance or inbreeding. It has largely been overlooked that there are a

16 substantial number of vertebrate species that reproduce clonally in nature. This review

17 highlights how use of these naturally evolved, phenotypically complex animals can push

18 the boundaries of traditional experimental design and contribute to answering fundamental

19 questions in the fields of ecology and evolution. 


\section{Introduction}

24 The ability to reliably generate genetically identical animals revolutionized science. Among

25 vertebrates, mice, rats, zebrafish and frogs have been bred into numerous isogenic lines

26 and even more species have successfully been cloned or genetically manipulated through

27 sophisticated molecular methods ${ }^{1}$. Use of these animals as replicate individuals has

28 allowed us to investigate and disentangle the relative influences of genetic and

29 environmental variation on the expression of key phenotypic traits ranging from molecular

30 patterns to behavior. This level of precision, however, comes at a cost: the genotypes of

31 these engineered vertebrates are not products of natural selection raising concerns about

32 the potential ecological relevance and generalizability of the expressed phenotypes ${ }^{2}$.

33 Because of this, many researchers in ecology and evolution have been reluctant to use

34 isogenic or cloned model systems.

To date, however, it has largely been overlooked that there are a substantial number

36 of vertebrate species that reproduce clonally, naturally. Since the identification of the first

37 naturally clonal, or unisexual, vertebrate in 1932, the Amazon molly (Poecilia formosa) ${ }^{3}$,

38 researchers have identified roughly 100 species, or 'biotypes' of unisexual vertebrates

39 across at least 22 genera of fish, amphibians and reptiles (Fig. 1) (-6 $^{4}$. The common

40 characteristic among these animals is that they reproduce without genetic recombination

41 thus producing broods or clutches of genetically identical offspring. Much of the previous

42 research on unisexual vertebrates has focused on questions relating to their unisexual 43 nature (Box 1).

$44 \quad$ Here, we argue that unisexual vertebrate animals offer a unique combination of traits

45 making them ideal systems for tackling many long-standing and emerging questions in 46 ecology and evolution ${ }^{7,8}$. As with traditional isogenic and cloned model systems they 
47 provide the opportunity to generate genetically identical replicate individuals within lineages

48 and exploit the genetic variation that is present among lineages (within a biotype). And in

49 contrast to many traditional vertebrate model systems like mammals, many unisexual

50 vertebrates require no parental care after birth, so in combination with their clonality,

51 researchers have an unparalleled ability to disentangle genetic from environmental

52 influences, including during very early life. These animals thus combine the highly

53 desirable experimental control of genes and environment with the phenotypic complexity of

54 vertebrates that have evolved under natural selection. Additionally, these animals are

55 geographically widespread both within and between biotypes, ecologically diverse, and can

56 often be studied under field conditions (Table 1). This enormous potential stands in sharp

57 contrast to the fact that unisexual vertebrates currently play at best a marginal role for 58 research in ecology and evolution.

59 Below we first outline basics of unisexual vertebrate reproductive biology; and then 60 our main goal in this review is to highlight how unisexual vertebrates can be used to push 61 the boundaries of classic experimental design, promoting novel insights into a range of 62 fundamental questions in ecology and evolution. We focus on four key areas where we see 63 the greatest potential 1) to better understand the genotype-phenotype link; 2) to better 64 investigate how animals integrate cues from multiple sources over ontogeny; 3 ) to test 65 theories about the processes generating phenotypic variation within populations and 4) to 66 generate replicate animal groups to investigate social and collective dynamics.

\section{Basics of unisexual reproductive biology}

69 There are a number of common characteristics shared by all unisexual vertebrates. First, 70 unisexuality appears to be limited to ectothermic animals, namely lizards, fish and 
71 amphibians ${ }^{4}$. Second, these animals are all-female lineages, hence the name 'unisexual' .

72 Finally, most if not all biotypes evolved as a result of a hybridization event between two 73 relatively closely related species ${ }^{9,}$ but see $^{10}$. A major advantage of their hybrid origin is that

74 these animals are often nearly completely heterozygous across their entire genome ${ }^{5,11}$,

75 helping to limit concerns about inbreeding depression that are typically raised with cloned

76 or isogenic animals. Additionally, recent work in the unisexual Amazon molly demonstrated

77 that the structure and continued evolution of its genome appears to match the processes

78 occurring in the genomes of its sexual ancestors in terms of gene conversion rates, 79 patterns of gene evolution and transposable element activity ${ }^{11}$. So while these animals 80 employ unique reproductive modes, their biology, ecology and molecular processes can 81 likely be generalized (to some extent) beyond this one species group.

82 Unisexual verterbrates reproduce using three main reproductive strategies: 83 parthenogenesis, gynogenesis and hybridogenesis (Fig. 2) ${ }^{5,6,9}$. These modes differ in 84 whether the eggs are reduced or not in chromosome number and whether they need 85 sperm to stimulate development. Parthenogenic animals are truly clonal in that they 86 generate unreduced eggs with no recombination and without external input (i.e. sperm) 87 from another animal, though in some biotypes, pseudo-copulation with another female 88 appears to enhance reproductive success ${ }^{12}$. This mode of reproduction is (in vertebrates) 89 only found in Squamate lizards and snakes $^{13}$. Gynogenetic vertebrates also produce 90 unreduced eggs, but require sperm from a related species to stimulate embryonic 91 development, though this genetic material is generally not incorporated into the egg ${ }^{14}$. 92 Hybridogenetic animals retain some hallmarks of sexual reproduction: they produce 93 reduced eggs without recombination containing just one parental genome, generally the 94 maternal genome, discarding the other. The egg is fertilized with sperm, producing a 
95 diploid offspring. As such, one genome (the maternal) is inherited clonally through the 96 lineage, and the other (the paternal) is inherited sexually anew each generation ${ }^{9}$. This 97 reproductive mode has also been called hemiclonality ${ }^{9}$. Unisexual biotypes can arise either 98 through a single hybridization event (e.g. the gynogenetic fish $P$. formosa ${ }^{15,16}$ ), where all 99 genetic variation among lineages is a result of subsequent mutations or introgression, or 100 through multiple hybridizations and backcrossings (e.g. the parthenogenetic gecko 101 Heteronotia binoei ${ }^{17}$ ) resulting in extensive genetic variation among lineages. As such, all 102 biotypes exhibit some level of clonal diversity offering the opportunity for researchers to 103 investigate their questions across multiple genetic backgrounds.

We note that at least two other modes of reproduction exist among vertebrates that 105 result in genetically identical offspring: polyembryony and constitutive self-fertilization. 106 Polyembryony occurs through the splitting of a single embryo such as in monozygotic twins 107 (or triplets, etc). However, each embryo is the result of sexual reproduction so while 108 siblings are clones within a generation, there is no maintenance of a clonal lineage across 109 generations ${ }^{18}$. While common in plants and invertebrates, especially parasitoid wasps, 110 polyembryony is confined to Dasypus armadillos in vertebrates ${ }^{18}$. Constitutive self-

111 fertiliziation is a form of inbreeding that over many generations results in essentially

112 homozygous clones. The only vertebrates known (so far) to constitutively self-fertilize are 113 the mangrove killifish (Kryptolebias marmoratus) and possibly the closely related 114 Kryptolebias ocellatus ${ }^{19}$. These modes are not strictly unisexual as recombination still 115 occurs, and are relatively rare among vertebrates but could still be utilized in much the 116 same way as we advocate for unisexual vertebrates.

117 The different unisexual reproductive modes can be advantageous for different 118 research questions and designs: parthenogenetic animals produce truly clonal offspring 
119 enabling powerful replicate individual approaches in vertebrates; so do gynogenetic

120 animals but here researchers can control when reproduction occurs by controlling females'

121 access to sperm. Hybridogenetic animals can be used to test the effects of one genomic

122 complement in multiple different genetic backgrounds which is especially useful for

123 questions on the causes and consequences of epistasis ${ }^{20}$. And so depending the desired

124 level of genetic control researchers could chose the species that exhibits the most

125 appropriate reproductive biology for their question of interest.

127 The link from genotype to phenotype

128 Advances in -omics technologies (e.g. genomics, transcriptomics, proteomics) have

129 provided major breakthroughs in understanding the pathways from genotype to phenotype.

130 These techniques have now been applied across a variety of animal systems ${ }^{21-23}$ but there

131 are still a number of limitations that can make it difficult to disentangle the molecular

132 underpinnings of ecologically and evolutionarily important traits. First, studies of differential

133 gene (or protein or metabolite) expression can be very noisy often because allelic variation

134 overshadows any treatment effects ${ }^{24-26}$. Second, a major goal is to understand the

135 temporal changes of expression profiles, but again, allelic variation among individuals often

136 clouds these dynamics. Third, the use of only a limited number of vertebrate models, such

137 as mice and rats, has biased gene discovery and annotation to often focus on loci with

138 human medical implications ${ }^{27}$. So from a methodological point of view, unisexual

139 vertebrates can provide serious advantages as model organisms in -omics studies.

140 Researchers can more precisely pinpoint expression differences by comparing groups of

141 these genetically identical animals. And sampling from groups of identically treated

142 unisexual vertebrates would offer a more intimate look into expression dynamics over time. 
143 A practical benefit is that researchers can likely reduce the number of biological replicates

144 as they will be able to capture the level of natural variation in expression with fewer 145 animals ${ }^{28}$.

146 At the forefront of this field is the study of how epigenetic mechanisms can give rise 147 to heritable phenotypic variation. Heritable changes in gene expression patterns can occur 148 through at least three pathways: DNA methylation, chemical changes to DNA-binding 149 proteins (e.g. histones) and regulation by small RNA molecules ${ }^{29}$. Importantly, these 150 mechanisms are themselves influenced by genetic variation and are inherently dynamic, 151 changing both within and between generations ${ }^{29}$. And so, a full understanding of what 152 ultimately generates differential gene expression requires model systems where genetic 153 and epigenetic variation can be studied independently ${ }^{21,30}$. Indeed, the use of naturally 154 inbred lines of plants (accessions) such as Arabidopsis, or asexual lineages of 155 invertebrates such as Daphnia has highlighted the important role of epigenetic processes 156 in generating ecologically relevant phenotypic variation ${ }^{31}$. For example, recent work on 157 corals demonstrates the power of taking rigorous replicate individual approaches into an 158 ecological context. Corals can reproduce asexually through budding so parts of a single 159 colony (clone) can be separated and used as replicate 'individuals'. Using a reciprocal 160 transplant design, Kenkel and $\mathrm{Matz}^{24}$ tested how plasticity in gene expression mediates 161 local adaptation in a coral (Porites astreoides) across different environments. Because they 162 used genetically identical replicate individuals, they confirmed that a large part of these 163 expression differences must be due to epigenetic mechanisms. Oldach et al. ${ }^{32}$ also took 164 advantage of the clonal nature of coral to understand the molecular basis of reproductive 165 timing in Acropora gemmifera. They were able to repeatedly take tissue samples from the 166 same (clonal) coral over several weeks to precisely follow how gene expression in a given 
167 genotype responded to the lunar cycle. So far, such work has lagged behind in vertebrate

168 systems, likely because of the technical and logistical constraints imposed by most 169 (sexually reproducing) vertebrate animals. Here unisexual vertebrates offer the 170 experimental rigor typically associated with plant and invertebrate studies, opening up new 171 opportunities to investigate the molecular basis, particularly the epigenetic basis, of

172 ecologically relevant phenotypic traits across the animal kingdom.

173 Despite their genetic similarity there is still considerable phenotypic variation within 174 unisexual vertebrate lineages in many traits including behaviour ${ }^{33}$, life-history ${ }^{34}$ and 175 morphology ${ }^{35,36}$, suggesting epigenetic processes may be of particular biological 176 importance in these animals. DNA methylation is perhaps the best studied epigenetic

177 mechanism to date and unisexual vertebrates offer the ideal opportunity to disentangle its 178 role from that of genetic variation in producing phenotypic variation. This has been

179 exemplified with work done on Chrosomus eos-neogaeus, a diploid gynogenetic unisexual

180 fish from the hybridization of the finescale dace (C. neogaeus) and the northern redbelly 181 dace $(\text { C. eos })^{37}$. This species exhibits high levels of variation in methylation patterns (i.e.

182 epi-mutations or epi-alleles) across its genome ${ }^{38}$ and these methylation patterns correlate 183 with environmental variables among different populations ${ }^{39,40}$ suggesting such epi-

184 mutations may provide a mechanism to facilitate local adaptation in the absence of genetic 185 variation. An exciting area for future research would be to directly compare differences in 186 epigenetic mechanisms between unisexual biotypes and their sexual counterparts to test 187 the role of epigenetics in population persistence and adaptation. Here, gynogenetic 188 unisexuals will be especially powerful as they must co-exist with their sexual ancestors to 189 acquire sperm. For example, the unisexual Amazon molly ( $P$. formosa) can utilize sperm 190 from at least three other sexual molly species (P. latipinna, $P$. mexicana, $P$. latipunctata $)^{41}$ 
191 and thus is completely sympatric with at least one of these species across its entire

192 range ${ }^{41}$. This opens up the possibility for powerful comparisons between closely related 193 species that share half of their genome and occupy the same environments but differ in

194 reproductive mode. One might predict that unisexual vertebrates exhibit epigenetic 195 mechanisms that are more responsive to environmental cues compared to sexual species.

196 Indeed, despite asexual organisms generally being considered 'evolutionary dead-ends', 197 multiple unisexual vertebrate biotypes have persisted for hundreds of thousands ${ }^{16}$, or even 198 millions of years ${ }^{42}$ suggesting that these animals may exhibit particularly flexible and 199 sensitive epigenetic mechanisms ${ }^{43,44}$. Taken together epigenetic mechanisms may be 200 especially relevant within unisexual vertebrates offering the next major step forward in 201 understanding how animals can respond to environmental change in the absence of allelic 202 variation.

203

\section{Cue integration and development in labile traits}

205 A key aim in developmental and evolutionary biology is to understand how animals 206 integrate information from their genes, parents and environment to shape their phenotypes 207 over ontogeny ${ }^{45-47}$. The classic quantitative genetics view is that phenotypic variation 208 develops as a result of the combined influence of genetic and environmental variation ${ }^{48}$. 209 However, a limitation of this framework is that it is largely descriptive, being unable to make 210 mechanistic predictions about how different sources of variation result in changes to an 211 animal's phenotype. Such a mechanistic understanding is especially important for labile 212 traits, such as behavioral or physiological traits, which are repeatedly expressed and 213 modulated throughout an animal's lifetime. Because of this, recent authors suggest that a 214 complementary framework is needed that explicitly takes into account the path-dependent 
215 and iterative nature of ontogeny ${ }^{46,49,50}$. Indeed, there is accumulating evidence using

216 unisexual and other isogenic vertebrates showing that even genetically identical individuals

217 reared under essentially identical environments still exhibit considerable phenotypic

218 variation ${ }^{33,51-53}$. These findings highlight how our explanations of phenotypic variation will

219 remain incomplete if we do not explicitly consider developmental processes. In particular,

220 models incorporating Bayesian updating mechanisms and dynamic stochastic and/or

221 chaotic processes are well suited to explain and make predictions about how different cues

222 should be integrated over time ${ }^{45-47}$. Bayesian updating models generally have three main

223 components ${ }^{46,54,55}$ : first, an individual's prior information, which is their naïve assessment of

224 the environment before any experience with it; this is likely informed by cues it receives

225 from its genes and parents. Second, the likelihood function describes the likely state of the

226 environment given a particular cue, e.g. predator olfactory cues generally signal an

227 increased likelihood of a risky environment. These two components are then integrated to

228 generate the animal's posterior expectations, which can be considered their labile

229 phenotype. This dynamic framework can therefore explain and predict how an animal's

230 phenotype should develop dependent on genetic, parental and environmental cues.

231 Recent work has shown the potential of these theoretical-conceptual models in

232 explaining and predicting development in labile traits. Stein and colleagues used 233 threespined sticklebacks, Gasterosteus aculeatus, to manipulate two sources of cues:

234 parental and personal experience with predator cues $^{56}$. They found that sticklebacks adjust

235 their behavior and gene expression in response to these cues non-additively with the 236 presentation of cues as either parental or personal information generating similar 237 phenotypic responses in the offspring ${ }^{56}$. Other work using Drosophila instead manipulated 238 genetic and environmental cues to show that different genotypes respond to different 
239 environments in predictable ways ${ }^{57}$. Both studies provide support for key predictions from 240 information integration theory but were limited in manipulating only two cue sources.

241 Unisexual vertebrates would offer the next step forward by providing unparalleled control

242 over all cues in three main ways. First, in addition to providing replicate individuals of the 243 same genotype, these animals also provide the opportunity to manipulate genetic cues as

244 all biotypes of unisexual vertebrates contain multiple lineages (genotypes). Second, 245 unisexual vertebrates offer the opportunity to disentangle potential pre- and post-birth 246 maternal influences. This is because all unisexual vertebrates are either egg-laying or live247 bearing but with typically no parental care after birth. This means mothers have ample 248 opportunity to interact with their young pre-birth potentially providing maternal cues to their 249 offspring through manipulations to their offspring's gene expression (see above) and/or 250 variation in hormonal or resource deposition ${ }^{58}$. Third, once the offspring are born, 251 researchers have near complete control over early life personal experiences, which are 252 known to be especially foundational to phenotypic development ${ }^{59}$. Taken together, these 253 characteristics of unisexual vertebrates will allow researchers to substantially advance our 254 understanding of how individuals use, value and integrate information coming from multiple 255 sources to shape their phenotypes.

\section{Evolutionary emergence of individual variation}

258 A major goal in both ecology and evolution is to uncover the factors that drive and maintain 259 between-individual phenotypic variation within populations, particularly in behavior, 260 foraging specializations and cognition ${ }^{60-63}$. Much of the research in this field has been 261 theoretical-conceptual in nature ${ }^{60}$, and empirical evidence suggests a relationship between 262 patterns of variation and several ecological factors such as predation risk ${ }^{64,65}$ and social 
263 dynamics ${ }^{66,67}$. At least three (non-exclusive) classes of mechanisms have been proposed

264 to translate these ecological pressures into between-individual phenotypic variation:

265 (epi)genetic variation, cue integration over development and state-dependent feedbacks ${ }^{68-}$

$266{ }^{70}$. Unisexual vertebrates offer a step forward by allowing us to adopt a highly controlled 267 replicate individual approach to rigorously test many of the specific hypotheses associated 268 with these mechanisms. We have discussed above why and how unisexual vertebrates are 269 uniquely suited for the study of (epi-)genetic variation and cue integration. Here we 270 elaborate on how they can be leveraged to test the hypotheses associated with the idea 271 that state-dependent feedbacks are a major mechanism underlying individual variation.

272 A major body of theoretical-conceptual work has been developed on understanding 273 individual behavioral variation (i.e. animal personalities, or behavioral types) in terms of 274 how feedbacks between behavior and state variables (e.g. metabolic rate, residual 275 reproductive value, social positions) can generate and/or exaggerate consistent individual 276 behavioral variation ${ }^{60,71}$. While correlational studies of these ideas are common, rigorous 277 manipulative experimental tests are still rare - unisexual vertebrates are ideally suited to 278 make such tests. For example, while not strictly unisexual, the mangrove killifish 279 (Kryptolebias marmoratus) is a self-fertilizing hermaphroditic fish with multiple nearly 280 genetically identical lineages. Edenbrow \& $\mathrm{Croft}^{34,72}$ found that different genetic lineages of 281 this species exhibited differences in life-history traits ${ }^{34}$ and that these traits were also 282 influenced by environmental cues such as predation threat as predicted ${ }^{72}$. However, 283 somewhat unexpectedly they found that this natural variation in life-history traits did not 284 explain any variation in behavioral traits. This study highlights how the important next step 285 in this research area is to firmly test for causal links between state and behavior. Testing 286 the assumptions, and then predictions of these theories is critical: for example, whereas 
287 state variables are generally predicted to cause variation in behavior, Bijleveld and 288 colleagues $^{73}$ used an experimental approach to show that the opposite may also be true. 289 They manipulated the gizzard size, a major metabolic organ, of red knot birds and found no 290 resulting impacts on individual behavior. Rather, the animal's behavior seemed to predict 291 their gizzard size. This suggests there is a more complex interplay between state and 292 behavior than previously expected. These relationships can be rigorously disentangled 293 using unisexual vertebrates, for example, by experimentally manipulating individual states 294 (e.g. body condition, early-life experience) within the same clonal lineage and then 295 following any resulting impacts on behavior. Unisexual vertebrates are ectothermic 296 animals, and so researchers could manipulate body size by varying the thermal regime or 297 body fat by altering the lipid content in the animal's food, for example. Additionally, the 298 strength and direction of feedback loops are predicted to vary based on the fitness 299 landscape and species ecology. And so another experimental option would be to 300 systematically vary the costs and benefits of different behaviors and/or states by presenting 301 animals with predator cues or higher competition, for example, and investigate whether this 302 results in increased or decreased levels of individual behavioral variation as predicted by 303 the various theories. For example, if animals exhibit asset protection this is generally 304 predicted to result in negative feedbacks eroding behavioral variation, though some models 305 also suggest positive feedbacks can occur that would exaggerate individual 306 differences $^{74,75}$. Alternatively, state-dependent safety or starvation avoidance should 307 increase variation among individuals through positive feedback loops ${ }^{76,77}$. The use of 308 unisexual vertebrates and replicate individual approaches has the potential to revolutionize 309 the study of individual behavioral variation by pushing it from being a field that mainly 
310 documents the presence of this variation, to one that can predict when, how and why it 311 emerges.

\section{Social behavior and network structure}

314 Many animal species need to regularly interact with conspecifics and so understanding

315 social behavior and group dynamics is of central importance in animal biology. Questions 316 in this area relate to understanding the mechanisms that generate social behavior and

317 social structure, and then the consequences of these collective and group dynamics on

318 individual fitness ${ }^{78,79}$. A major limitation to testing these questions however is that when

319 using non-isogenic organisms, the individuals are always (genetically) different from each 320 other making true replication at the group level difficult. Similarly, any consequences of 321 group dynamics and social structure on the individual will be modulated by (genetic) 322 variation among individuals. As unisexual vertebrates exhibit a large diversity of social 323 structures ranging from highly social and schooling fish such as the Amazon molly, to more 324 solitary and territorial reptiles such as the whiptail lizards, Aspidoscelis biotypes ${ }^{9}$, these 325 animals provide a broad range of excellent model systems in which to study the interplay 326 between individual phenotypes and group dynamics in a true replicate individual and group 327 fashion.

328 Social networks describe and quantify the pattern of social interactions among 329 members of a group. A major question is to understand how and why the component parts 330 (i.e. individuals) give rise to key features of the group phenotype ${ }^{80,81}$ ? To this end, there is 331 recent work showing the long-lasting consequences of early life experiences on later adult 332 behavior in unisexual animals. Using the unisexual Amazon molly, Laskowski et al ${ }^{82}$ gave 333 genetically identical individuals different social experiences of either winning or losing 
334 aggressive encounters in the first few months of their lives. This early-life experience nearly

335 perfectly predicted their ability to achieve a high dominance rank in a group setting over six 336 months later after sexual maturity. As such, these genetically identical and size-matched 337 adult fish exhibited a reliable phenotype (dominance behavior) based exclusively on their 338 early life experience. This raises the possibility that researchers can generate individuals 339 with particular phenotypes allowing strong tests of how individual phenotypes and group 340 composition affect social dynamics and network structures. Indeed, the first major test will 341 be whether networks can be replicated and if this depends on the phenotypes of the 342 component individuals, or on external environmental influences. Work in great tits (Parus 343 major) suggest that social networks might be quite robust across contexts: Firth \& 344 Sheldon ${ }^{83}$ were able to manipulate the social network by altering which birds could access 345 particular feeding stations. The resulting changes in how individuals associated in a 346 foraging context carried over to how individuals associated in a mating context. Using 347 unisexual vertebrates, researchers could build on this to more closely investigate the 348 mechanisms generating particular network structures. One might predict that within a given 349 environment, a group of genetically identical individuals should reliably exhibit the same 350 network structure. The next step would be to test how the external environment, such as 351 threat of predation or resource availability modulates the network structure and how 352 persistent these changes are. Using a replicate individual (and group) approach would also 353 allow researchers to disentangle between effects driven purely by group size versus by 354 phenotypic composition of the group. For example, in collective decision making, larger 355 groups frequently perform better but it is often unclear whether this is caused by the group 356 size, per se, or the fact that larger groups are more likely to harbor a high performing 357 individual $^{84}$. 
Once groups are created, the next step is to test how different network structures

359 feedback to influence individual and group success. Social network structure is predicted to 360 influence such processes as information (or disease) transfer and collective 361 behaviours ${ }^{78,79}$. For example, Aplin and colleagues $^{85}$ tracked the spread of information 362 through flocks of great tits by teaching only particular individuals a novel way to access 363 food from an experimental feeder. They were then able to follow how these feeding 364 strategies spread through the network. Unisexual vertebrates provide the opportunity to 365 build on this work by allowing researchers to replicate and manipulate social networks, a 366 persistent challenge in most (sexually reproducing) species. For example, testing disease 367 transmission dynamics could be especially fruitful in unisexual vertebrates as their genetic 368 similarity removes the possibility that some individuals may be more or less susceptible to 369 the disease or parasite of interest. In addition, researchers could manipulate lineage 370 (genotypic) composition within groups to explicitly test the role of genetic variation in 371 transmission dynamics. Understanding how group structure influences individual fitness 372 could provide valuable insights into other social dynamics such as partner choice, predator 373 avoidance and social cohesion. Taken together, the ability to replicate groups and 374 potentially generate individuals with desired phenotypes through careful breeding make 375 unisexual vertebrates ideally suited for investigating questions about the causes and 376 consequences of network structures.

\section{Summary \& conclusions}

379 Unisexual vertebrates offer the experimental control of the traditional isogenic and cloned 380 animal model systems with the ecological realism of a phenotypically complex naturally 381 evolved vertebrate (Box 2). This group of animals is biologically diverse containing at least 
382100 biotypes exhibiting different reproductive modes, social structures and life-history 383 strategies. Many of these species can be easily kept and bred in the lab, and can also 384 studied under field conditions making them highly desirable as study organisms for 385 questions in ecology and evolution. Of course, no system is without some drawbacks and 386 unisexual vertebrates will not be appropriate for every question. The biology and ecology of 387 the animal will ultimately determine their suitability for a specific research question and this 388 should be carefully considered before adopting any new study system. Nevertheless, we 389 urge researchers to consider the suitability of these amazing animals to help them 390 rigorously test hypotheses about fundamental questions in ecology and evolution in 391 creative and novel ways.

392

393

394 
395 
Table 1. General ecological characteristics of selected unisexual vertebrates. Under "Repro. Mode", H stands for hybridogenesis, G stands for gynogenesis and P stands for parthenogenesis. More complete lists of known unisexual vertebrates can be found $\mathrm{in}^{6,9}$

\begin{tabular}{|c|c|c|c|c|}
\hline Species & $\begin{array}{l}\text { Repro. } \\
\text { mode }\end{array}$ & $\begin{array}{l}\text { Ploidy \& } \\
\text { ancestral } \\
\text { species }\end{array}$ & Range \& ecological notes & Ref \\
\hline $\begin{array}{l}\text { Amazon molly } \\
\text { Poecilia formosa }\end{array}$ & $\mathrm{G}$ & $\begin{array}{l}\text { Diploid } \\
\text { P.mexicana, } \\
\text { P.latipinna }\end{array}$ & $\begin{array}{l}\text { Southern Texas and Gulf coast of } \\
\text { Mexico. Occupies small, slow-moving } \\
\text { freshwater bodies. Highly gregarious } \\
\text { live-bearer. Produces broods ( } 10-50 \\
\text { offspring) } 2-4 \text { times per year. }\end{array}$ & 41,86 \\
\hline $\begin{array}{l}\text { Topminnows and } \\
\text { livebearers } \\
\text { Poeciliopsis spp. }\end{array}$ & $\mathrm{G}, \mathrm{H}$ & $\begin{array}{l}\text { Diploid \& triploid } \\
\text { biotypes } \\
\text { P. lucida, } \\
\text { P. monacha, } \\
\text { P. latidens, } \\
P . \text { occidentalis }\end{array}$ & $\begin{array}{l}\text { Baja coast of Mexico. Occupies small } \\
\text { freshwater bodies in desert habitats. } \\
\text { Likely experiences high competition } \\
\text { during dry seasons. Highly gregarious } \\
\text { live-bearer. }\end{array}$ & 87,88 \\
\hline $\begin{array}{l}\text { Spined loaches } \\
\text { Cobitis spp. }\end{array}$ & $\mathrm{G}$ & $\begin{array}{l}\text { Triploid and } \\
\text { tetraploid } \\
\text { biotypes } \\
\text { C. taenia, } \\
\text { C. elongatoides, } \\
\text { C. tanaitica, } \\
\text { C. taurica, } \\
\text { C. strumicae, } \\
\text { C. melanoleuca }\end{array}$ & $\begin{array}{l}\text { Widespread across non-Mediterranean } \\
\text { Europe. Bottom-dwelling and often } \\
\text { buries itself in the substrate of rivers. } \\
\text { Mostly nocturnal. Mostly solitary egg- } \\
\text { layer. Spawns once per year. }\end{array}$ & $89-91$ \\
\hline $\begin{array}{l}\text { Mole } \\
\text { salamanders } \\
\text { Ambystoma spp. }\end{array}$ & $\mathrm{G}, \mathrm{H}$ & $\begin{array}{l}\text { Several } \\
\text { polyploid } \\
\text { biotypes } \\
\text { A. laterale, } \\
\text { A. texanum, } \\
\text { A. } \\
\text { jeffersonianum, } \\
\text { A. tigrinum }\end{array}$ & $\begin{array}{l}\text { Around the Great Lakes region and } \\
\text { Northeastern North America. Terrestrial } \\
\text { in wooded areas but lays eggs in (often } \\
\text { ephemeral) ponds. Generally solitary. } \\
\text { Likely the oldest unisexual vertebrates } \\
(\sim 2-4 \text { mya) }\end{array}$ & 42,92 \\
\hline $\begin{array}{l}\text { Edible water } \\
\text { frogs } \\
\text { Pelophylax } \\
\text { esculentus } \\
\text { (formerly Rana } \\
\text { esculenta) }\end{array}$ & $\mathrm{H}$ & $\begin{array}{l}\text { Diploid \& triploid } \\
\text { biotypes } \\
\text { P.lessonae, } \\
\text { P.ridibunda }\end{array}$ & $\begin{array}{l}\text { Widespread across non-Mediterranean } \\
\text { Europe. Occupies (sometimes } \\
\text { ephemeral) freshwater bodies where } \\
\text { they lay their eggs. Biotypes often } \\
\text { contain males (which also reproduce } \\
\text { hybridogenetically) }\end{array}$ & 93,94 \\
\hline $\begin{array}{l}\text { Whiptail lizards } \\
\text { Aspidoscelis } \\
\text { tesselatus } \\
\text { (formerly } \\
\text { Cnemidophorus) }\end{array}$ & $P$ & $\begin{array}{l}\text { Diploid } \\
\text { A. tigris } \\
\text { marmorata, } \\
\text { A. gularis } \\
\text { septemvittata }\end{array}$ & $\begin{array}{l}\text { Common across the southwestern US } \\
\text { and central-northern Mexico. Occupies } \\
\text { dry, scrublands and seems to prefer } \\
\text { human-disturbed areas. Egg-laying. } \\
\text { Generally solitary and diurnal. }\end{array}$ & 95,96 \\
\hline $\begin{array}{l}\text { Caucasian rock } \\
\text { lizard } \\
\text { Lacerta } \\
\text { armeniaca }\end{array}$ & $\mathrm{P}$ & $\begin{array}{l}\text { Diploid } \\
\text { L. mixta, } \\
\text { L. valentini }\end{array}$ & $\begin{array}{l}\text { Between Black and Caspian seas } \\
\text { (Turkey, Georgia, Armenia). Occurs in } \\
\text { rocky forests and seems to prefer drier } \\
\text { areas. Generally solitary. Egg-laying. }\end{array}$ & 97,98 \\
\hline
\end{tabular}


401 Figure Captions

402 Figure 1: Three examples of unisexual vertebrates. There are over 100 known biotypes 403 of unisexual vertebrates, all of which are reptiles, fish and amphibians.

404

405 Figure 2: Modes of unisexual reproduction. All unisexual vertebrates reproduce without 406 genetic recombination. Parthenogenic and gynogenetic animals produce unreduced eggs 407 containing the complete genome of the mother; gynogenetic eggs must be stimulated with 408 the sperm of another species (usually one of the sexual ancestral species) to begin 409 development though the genetic material from the sperm is discarded. Hybriogenetic 410 animals produce reduced eggs containing only half of the mother's genome, usually the 411 maternal half. The egg is then fertilized with the sperm of another species producing a 412 diploid offspring with a new paternal half of its genome. 
414 Box 1 | Examples of previous research with unisexual vertebrates

416 Research on unisexual vertebrates has addressed a wealth of questions but often focusing

417 on questions related to their nature - that is, how does (a)sexuality emerge and persist and

418 what are its consequences for the species' ecology and evolution? To illustrate some of

419 this breadth, here we highlight research surrounding three different unisexual vertebrates.

\section{Aspidoscelis whiptail lizards (formerly Cnemidophorus)}

422 While the phylogeny of this genus is still not fully resolved, it appears that many, perhaps

423 up to half, of the species in this group are parthenogenic ${ }^{99,100}$. Previous work on this group

424 generated the 'Balance Hypothesis' whereby successful hybridization between two sexual

425 species requires them to be phylogenetically distant enough that normal meiosis is

426 disrupted, but not so distant as to lead to aberrant development ${ }^{101}$. Many of the resulting

427 biotypes are triploid ${ }^{13}$, generally with two genomic complements from one ancestral

428 species and just one from the other, though at least one biotype has genomic complements

429 from three different ancestral species (Aspidoscelis exsanguis ${ }^{102}$ ). And so these lizards

430 have been particularly useful for investigating how they resolve the genomic conflict

431 between their different genomic complements ${ }^{13}$. At least one sexual species pair has been

432 successfully bred in the lab to generate a new parthenogenetic biotype in an example of

433 instantaneous speciation ${ }^{103}$ offering key insights into the molecular mechanisms underlying

434 (the lack of) recombination during meiosis ${ }^{13}$.

\section{Poecilia formosa, the Amazon molly}

436 As a gynogenetic animal, the Amazon molly requires sperm from one of her two ancestral 437 species, the sailfin or Atlantic mollies ( $P$. latipinna, $P$. mexicana) or a third closely related 
438 species (P. latipunctata) to stimulate embryonic development ${ }^{15,41}$. As such, it is completely 439 sympatric with at least one of its host species across its entire range and has been used to 440 investigate how species interactions can stabilize the co-existence of such asexual/sexual

441 complexes. These sympatric species differ little in dietary preferences ${ }^{104}$ and parasitism 442 rates $^{105}$, and while males of $P$. latipinna and $P$. mexicana prefer to mate with their own 443 conspecific females they will mate with the unisexual P.formosa especially as this appears 444 to increase their attractiveness to their own females through mate-choice copying ${ }^{106}$.

\section{Poeciliopsis monacha-lucida-occidentalis complex}

446 This group consists of several hybridogenetic or gynogenetic biotypes ${ }^{107}$. The recurrent

447 hybridizations between the unisexual biotypes and sexual ancestral species has resulted in

448 considerable standing clonal diversity ${ }^{108}$. Vrijenhoek ${ }^{109}$ developed the 'Frozen Niche

449 Variation' hypothesis to explain how each clonal variant 'freezes' a combination of traits in

450 a lineage and those lineages within the least ecological overlap with the parental species

451 are most likely persist. This type of 'inter-clonal selection' or 'clonal sorting' offers a

452 mechanism to explain the persistence of these asexual lineages with the sexual ancestral

453 species and is supported from evidence from this ${ }^{110}$ and other unisexual species ${ }^{111}$. 
456 Box 2 | Potential of unisexual vertebrates in ecology \& evolution research

457 Unisexual vertebrates have a number of characteristics that make them ideal systems to 458 address long-standing and emerging questions of importance in ecology and evolution: 1)

459 individuals are genetically identical within lineages, 2) offspring typically do not require 460 parental care after birth, 3) their genotypes are ecologically relevant as products of natural

461 selection and 4) they are geographically, ecologically and phenotypically diverse species.

462 In our review, we highlight how these animals can be used to break new ground in four key

463 research areas.

464 Molecular mechanisms

$465 \quad$ Key advantage: Disentangle genetic from epigenetic variation

- How do epigenetic processes shape local adaptation?

- What are the temporal dynamics in expression profiles?

- Are epigenetic mechanisms more environmentally responsive in unisexual vertebrates?

470 Developmental processes

471 Key advantage: Control and manipulate sources of variation

- How do individuals integrate genetic, parental and environmental information over ontogeny?

- When and why do individuals value some types of information more than others?

- What are the mechanisms through which non-genetic maternal information transfer ccurs?

Individual variation 
- What environmental factors modulate the strength and direction of feedbacks between state and behavior?

482 Group dynamics

$483 \quad$ Key advantage: Replicate groups

- Do groups of genetically identical animals in identical environments develop similar social networks?

- How do environmental factors modulate network structure?

- How does network structure influence individual fitness and group performance? 


\section{References}

505

5061 Edwards, J. et al. Cloning adult farm animals: a review of the possibilities and problems

507 associated with somatic cell nuclear transfer. American Journal of Reproductive Immunology

$508 \quad 50,113-123(2003)$.

5092 Bolker, J. Model organisms: There's more to life than rats and flies. Nature 491, 31-33

$510 \quad$ (2012).

5113 Hubbs, C. L. \& Hubbs, L. C. Apparent parthenogenesis in nature, in a form of fish of hybrid

512

5134

514

515

$516 \quad 5$

517

5186

519

520

521

522

523

524

525

526

527

528

529

530

531

532

533

534

535

536

537

538

539

540

541

542

543

544

545

546 origin. Science 76, 628-630 (1932).

4 Vrijenhoek, R. C., Dawley, R. M., Cole, C. J. \& Bogart, J. P. in Evolution and Ecology of Unisexual Vertebrates Vol. 466 (eds Robert M Dawley \& James P Bogart) 19-23 (New York State Museum Bulletin, 1989).

5 Neaves, W. B. \& Baumann, P. Unisexual reproduction among vertebrates. Trends in Genetics 27, 81-88 (2011).

6 Avise, J. Clonality: the genetics, ecology, and evolution of sexual abstinence in vertebrate animals. (Oxford University Press, 2008).

7 Vrijenhoek, R. C. Unisexual fish: model systems for studying ecology and evolution. Annual Review of Ecology and Systematics 25, 71-96 (1994).

8 Crews, D. in Evolution and Ecology of Unisexual Vertebrates (eds Robert M Dawley \& James P Bogart) 132-143 (New York State Museum, 1989).

9 Dawley, R. M. \& Bogart, J. P. Evolution and Ecology of Unisexual Vertebrates. Vol. 466 (New York State Museum Bulletin, 1989).

10 Sinclair, E. A., Pramuk, J. B., Bezy, R. L., Crandall, K. A. \& Sites Jr, J. W. DNA evidence for nonhybrid origins of parthenogenesis in natural populations of vertebrates. Evolution 64, 1346-1357 (2010).

11 Warren, W. C. et al. Clonal polymorphism and high heterozygosity in the celibate genome of the Amazon molly. Nature Ecology \& Evolution 2, 669 (2018).

12 Crews, D., Grassman, M. \& Lindzey, J. Behavioral facilitation of reproduction in sexual and unisexual whiptail lizards. Proceedings of the National Academy of Sciences 83, 9547-9550 (1986).

13 Fujita, M. \& Moritz, C. Origin and evolution of parthenogenetic genomes in lizards: current state and future directions. Cytogenetic and Genome Research 127, 261-272 (2009).

14 Schlupp, I. The evolutionary ecology of gynogenesis. Annual Review of Ecology, Evolution, and Systematics, 399-417 (2005).

15 Lampert, K. \& Schartl, M. The origin and evolution of a unisexual hybrid: Poecilia formosa. Philosophical Transactions of the Royal Society of London B: Biological Sciences 363, 2901-2909 (2008).

16 Stoeck, M., Lampert, K. P., Moeller, D., Schlupp, I. \& Schartl, M. Monophyletic origin of multiple clonal lineages in an asexual fish (Poecilia formosa). Molecular Ecology 19, 52045215 (2010).

17 Moritz, C., Donnellan, S., Adams, M. \& Baverstock, P. The origin and evolution of parthenogenesis in Heteronotia binoei (Gekkonidae): extensive genotypic diversity among parthenogens. Evolution 43, 994-1003 (1989). 
Craig, S. F., Slobodkin, L. B., Wray, G. A. \& Biermann, C. H. The 'paradox' of polyembryony: a review of the cases and a hypothesis for its evolution. Evolutionary Ecology 11, 127-143 (1997).

Tatarenkov, A., Lima, S. M., Taylor, D. S. \& Avise, J. C. Long-term retention of selffertilization in a fish clade. Proceedings of the National Academy of Sciences 106, 1445614459 (2009).

20 Abbott, J. K. \& Morrow, E. H. Obtaining snapshots of genetic variation using hemiclonal analysis. Trends in Ecology \& Evolution 26, 359-368 (2011).

21 Bossdorf, O., Richards, C. L. \& Pigliucci, M. Epigenetics for ecologists. Ecology Letters 11, 106-115 (2008).

22 Ekblom, R. \& Galindo, J. Applications of next generation sequencing in molecular ecology of non-model organisms. Heredity 107, 1-15 (2011).

23 Matz, M. V. Fantastic beasts and how to sequence them: ecological genomics for obscure model organisms. Trends in Genetics 34, 121-132 (2017).

24 Kenkel, C. D. \& Matz, M. V. Gene expression plasticity as a mechanism of coral adaptation to a variable environment. Nature Ecology \& Evolution 1, 0014 (2016).

25 Oleksiak, M. F., Churchill, G. A. \& Crawford, D. L. Variation in gene expression within and among natural populations. Nature Genetics 32, 261 (2002).

26 Crowley, J. J. et al. Analyses of allele-specific gene expression in highly divergent mouse crosses identifies pervasive allelic imbalance. Nature Genetics 47, 353-360 (2015).

27 Brenowitz, E. A. \& Zakon, H. H. Emerging from the bottleneck: benefits of the comparative approach to modern neuroscience. Trends in Neurosciences 38, 273-278 (2015).

28 Todd, E. V., Black, M. A. \& Gemmell, N. J. The power and promise of RNA-seq in ecology and evolution. Molecular Ecology 25, 1224-1241 (2016).

29 Bird, A. DNA methylation patterns and epigenetic memory. Genes \& Development 16, 6-21 (2002).

30 Verhoeven, K. J. F. \& Preite, V. Epigenetic variation in asexually reproducing organisms. Evolution 68, 644-655, doi:doi:10.1111/evo.12320 (2014).

31 Kalisz, S. \& Purugganan, M. D. Epialleles via DNA methylation: consequences for plant evolution. Trends in Ecology \& Evolution 19, 309-314 (2004).

32 Oldach, M. J., Workentine, M., Matz, M. V., Fan, T. Y. \& Vize, P. D. Transcriptome dynamics over a lunar month in a broadcast spawning acroporid coral. Molecular Ecology 26, 2514-2526 (2017).

33 Bierbach, D., Laskowski, K. L. \& Wolf, M. Behavioural individuality in clonal fish arises despite near-identical rearing conditions. Nature Communications 8, 15361 (2017).

34 Edenbrow, M. \& Croft, D. Behavioural types and life history strategies during ontogeny in the mangrove killifish, Kryptolebias marmoratus. Animal Behaviour 82, 731-741 (2011).

35 Schlosser, I. J., Doeringsfeld, M. R., Elder, J. F. \& Arzayus, L. F. Niche relationships of clonal and sexual fish in a heterogeneous landscape. Ecology 79, 953-968 (1998).

36 Cole, C. J., Taylor, H. L. \& Townsend, C. R. Morphological variation in a unisexual whiptail lizard (Aspidoscelis exsanguis) and one of its bisexual parental species (Aspidoscelis inornata)(Reptilia: Squamata: Teiidae): is the clonal species less variable? American Museum Novitates, 1-20 (2016).

37 Dawley, R. M., Schultz, R. J. \& Goddard, K. A. Clonal reproduction and polyploidy in unisexual hybrids of Phoxinus eos and Phoxinus neogaeus (Pisces; Cyprinidae). Copeia, 275-283 (1987).

38 Massicotte, R., Whitelaw, E. \& Angers, B. DNA methylation: a source of random variation in natural populations. Epigenetics 6, 421-427 (2011). 
604

605

606

607

608

609

610

611

612

613

614

615

616

617

618

619

620

621

622

623

624

625

626

627

628

629

630

$631 \quad 54$

632

633

634

635

636

637

638

639

640

641

39 Massicotte, R. \& Angers, B. General-purpose genotype or how epigenetics extend the flexibility of a genotype. Genetics Research International 2012 (2012).

40 Leung, C., Breton, S. \& Angers, B. Facing environmental predictability with different sources of epigenetic variation. Ecology and Evolution 6, 5234-5245 (2016).

41 Schlupp, I., Parzefall, J. \& Schartl, M. Biogeography of the Amazon molly, Poecilia formosa. Journal of Biogeography 29, 1-6 (2002).

$42 \mathrm{Bi}, \mathrm{K}$. \& Bogart, J. P. Time and time again: unisexual salamanders (genus Ambystoma) are the oldest unisexual vertebrates. BMC Evolutionary Biology 10, 238 (2010).

43 Castonguay, E. \& Angers, B. The key role of epigenetics in the persistence of asexual lineages. Genetics Research International 2012 (2012).

44 Vogt, G. Facilitation of environmental adaptation and evolution by epigenetic phenotype variation: insights from clonal, invasive, polyploid, and domesticated animals.

Environmental Epigenetics 3, dvx002 (2017).

45 McNamara, J. M., Dall, S. R. X., Hammerstein, P. \& Leimar, O. Detection vs. selection: integration of genetic, epigenetic and environmental cues in fluctuating environments. Ecology Letters 19, 1267-1276 (2016).

46 Stamps, J. A. \& Frankenhuis, W. E. Bayesian models of development. Trends in Ecology \& Evolution 31, 260-268 (2016).

47 Dall, S. R., McNamara, J. M. \& Leimar, O. Genes as cues: phenotypic integration of genetic and epigenetic information from a Darwinian perspective. Trends in Ecology \& Evolution 30, 327-333 (2015).

48 Mackay, T. F. The genetic architecture of quantitative traits. Annual Review of Genetics 35, 303-339 (2001).

49 Fisher, D. N., Brachmann, M. \& Burant, J. B. Complex dynamics and the development of behavioural individuality. Animal Behaviour 138, e1-e6 (2018).

50 Frankenhuis, W. E. \& Panchanathan, K. Balancing sampling and specialization: An adaptationist model of incremental development. Proceedings of the Royal Society of London B: Biological Sciences, rspb20110055 (2011).

51 Freund, J. et al. Emergence of individuality in genetically identical mice. Science 340, 756759 (2013).

52 Vogt, G. et al. Production of different phenotypes from the same genotype in the same environment by developmental variation. Journal of Experimental Biology 211, 510-523 (2008).

53 Gärtner, K. A third component causing random variability beside environment and genotype. A reason for the limited success of a 30 year long effort to standardize laboratory animals? Laboratory Animals 24, 71-77 (1990).

54 McNamara, J. M., Green, R. F. \& Olsson, O. Bayes' theorem and its applications in animal behaviour. Oikos 112, 243-251 (2006).

55 Trimmer, P. C. et al. Decision-making under uncertainty: biases and Bayesians. Animal Cognition 14, 465-476 (2011).

56 Stein, L. R., Bukhari, S. A. \& Bell, A. M. Personal and transgenerational cues are nonadditive at the phenotypic and molecular level. Nature Ecology \& Evolution 2, 13061311 (2018).

57 Stamps, J. A., Biro, P. A., Mitchell, D. J. \& Saltz, J. B. Bayesian updating during development predicts genotypic differences in plasticity. Evolution (2018).

58 Mousseau, T. A. \& Fox, C. W. The adaptive significance of maternal effects. Trends in Ecology \& Evolution 13, 403-407 (1998). 
642

643

644

645

646

647

648

649

650

651

652

653

654

655

656

657

658

659

660

661

662

663

664

665

666

667

668

669

670

671

672

673

674

675

676

677

678

679

680

681

682

683

684

685

686

687

59 Weaver, I. C. et al. Epigenetic programming by maternal behavior. Nature Neuroscience 7, 847-854 (2004).

60 Dingemanse, N. J. \& Wolf, M. Recent models for adaptive personality differences: a review. Philosophical Transactions of the Royal Society B: Biological Sciences 365, 3947-3958 (2010).

61 Bolnick, D. I. et al. The ecology of individuals: incidence and implications of individual specialization. The American Naturalist 161, 1-28 (2003).

62 Toscano, B. J., Gownaris, N. J., Heerhartz, S. M. \& Monaco, C. J. Personality, foraging behavior and specialization: integrating behavioral and food web ecology at the individual level. Oecologia 182, 55-69 (2016).

63 Thornton, A. \& Lukas, D. Individual variation in cognitive performance: developmental and evolutionary perspectives. Philosophical Transactions of the Royal Society B: Biological Sciences 367, 2773-2783 (2012).

64 Dingemanse, N. J. et al. Behavioural syndromes differ predictably between 12 populations of three-spined stickleback. Journal of Animal Ecology 76, 1128-1138 (2007).

65 Bell, A. M. \& Sih, A. Exposure to predation generates personality in threespined sticklebacks (Gasterosteus aculeatus). Ecology Letters 10, 828-834 (2007).

Laskowski, K. L. \& Bell, A. M. Competition avoidance drives individual differences in response to a changing food resource in sticklebacks. Ecology Letters 16, 746-753 (2013).

Laskowski, K. L. \& Pruitt, J. N. Evidence of social niche construction: persistent and repeated social interactions generate stronger personalities in a social spider. Proceedings of the Royal Society B: Biological Sciences 281, 20133166 (2014).

68 Stamps, J. A. \& Krishnan, V. Combining information from ancestors and personal experiences to predict individual differences in developmental trajectories. The American Naturalist 184, 647-657 (2014).

69 Dall, S. R., Houston, A. I. \& McNamara, J. M. The behavioural ecology of personality: consistent individual differences from an adaptive perspective. Ecology Letters 7, 734-739 (2004).

70 Biro, P. A. \& Stamps, J. A. Are animal personality traits linked to life-history productivity? Trends in Ecology \& Evolution 23, 361-368 (2008).

71 Wolf, M. \& Weissing, F. J. An explanatory framework for adaptive personality differences. Philosophical Transactions of the Royal Society B: Biological Sciences 365, 3959-3968, doi:10.1098/rstb.2010.0215 (2010).

72 Edenbrow, M. \& Croft, D. Environmental and genetic effects shape the development of personality traits in the mangrove killifish Kryptolebias marmoratus. Oikos (2012).

73 Bijleveld, A. I. et al. Personality drives physiological adjustments and is not related to survival. Proceedings of the Royal Society B: Biological Sciences 281 (2014).

74 Clark, C. W. Antipredator behavior and the asset-protection principle. Behavioral Ecology $\mathbf{5}$, 159-170, doi:10.1093/beheco/5.2.159 (1994).

75 Wolf, M., van Doorn, G. S., Leimar, O. \& Weissing, F. J. Life-history trade-offs favour the evolution of animal personalities. Nature 447, 581-584 (2007).

76 Luttbeg, B. \& Sih, A. Risk, resources and state-dependent adaptive behavioural syndromes. Philosophical Transactions of the Royal Society B: Biological Sciences 365, 3977-3990 (2010).

77 Mathot, K. J. \& Dall, S. R. Metabolic rates can drive individual differences in information and insurance use under the risk of starvation. The American Naturalist 182, 611-620 (2013). 
693

694

695

696

697

698

699

700

701

702

703

704

705

706

707

708

709

710

711

712

713

714

715

716

717

718

719

720

721

722

723

724

725

726

727

728

729

730

731

732

733

Kurvers, R. H. J. M., Krause, J., Croft, D. P., Wilson, A. D. M. \& Wolf, M. The evolutionary and ecological consequences of animal social networks: emerging issues. Trends in Ecology \& Evolution 29, 326-335 (2014).

Krause, J. \& Ruxton, G. D. Living in Groups. (Oxford University Press, 2002).

Farine, D. R. \& Whitehead, H. Constructing, conducting and interpreting animal social network analysis. Journal of Animal Ecology 84, 1144-1163 (2015).

81 Wolf, M. \& Krause, J. Why personality differences matter for social functioning and social structure. Trends in Ecology \& Evolution 29, 306-308, doi:http://dx.doi.org/10.1016/j.tree.2014.03.008 (2014).

82 Laskowski, K. L., Wolf, M. \& Bierbach, D. The making of winners (and losers): how early dominance interactions determine adult social structure in a clonal fish. Proceedings of the Royal Society B: Biological Sciences 283, 20160183 (2016).

83 Firth, J. A. \& Sheldon, B. C. Experimental manipulation of avian social structure reveals segregation is carried over across contexts. Proceedings of the Royal Society of London B: Biological Sciences 282, 20142350 (2015).

84 Liker, A. \& Bókony, V. Larger groups are more successful in innovative problem solving in house sparrows. Proceedings of the National Academy of Sciences 106, 7893-7898 (2009).

85 Aplin, L. M. et al. Experimentally induced innovations lead to persistent culture via conformity in wild birds. Nature 518, 538 (2015).

86 Costa, G. C. \& Schlupp, I. Biogeography of the Amazon molly: ecological niche and range limits of an asexual hybrid species. Global Ecology and Biogeography 19, 442-451 (2010).

87 Schultz, R. J. in Evolution and genetics of life histories 103-119 (Springer, 1982).

88 Quattro, J. M., Avise, J. C. \& Vrijenhoek, R. C. An ancient clonal lineage in the fish genus Poeciliopsis (Atheriniformes: Poeciliidae). Proceedings of the National Academy of Sciences 89, 348-352 (1992).

89 Bohlen, J. \& Ráb, P. Species and hybrid richness in spined loaches of the genus Cobitis (Teleostei: Cobitidae), with a checklist of European forms and suggestions for conservation. Journal of Fish Biology 59, 75-89 (2001).

90 Janko, K. et al. Diversity of European spined loaches (genus Cobitis L.): an update of the geographic distribution of the Cobitis taenia hybrid complex with a description of new molecular tools for species and hybrid determination. Journal of Fish Biology 71, 387-408 (2007).

91 Choleva, L., Apostolou, A., Rab, P. \& Janko, K. Making it on their own: sperm-dependent hybrid fishes (Cobitis) switch the sexual hosts and expand beyond the ranges of their original sperm donors. Philosophical Transactions of the Royal Society of London B: Biological Sciences 363, 2911-2919 (2008).

92 Bogart, J. P., Bi, K., Fu, J., Noble, D. W. \& Niedzwiecki, J. Unisexual salamanders (genus Ambystoma) present a new reproductive mode for eukaryotes. Genome 50, 119-136 (2007).

93 Berger, L. in The reproductive biology of amphibians 367-388 (Springer, 1977).

94 Graf, J.-D. \& Polls Pelaz, M. in Evolution and Ecology of Unisexual Vertebrates Vol. 466 (eds Robert M Dawley \& James P Bogart) 289-301 (New York State Museum Bulletin, 1989).

95 Taylor, H. L., Cole, C. J., Dessauer, H. C. \& Parker Jr, E. Congruent patterns of genetic and morphological variation in the parthenogenetic lizard Aspidoscelis tesselata (Squamata: Teiidae) and the origins of color pattern classes and genotypic clones in eastern New Mexico. American Museum Novitates, 1-40 (2003). 
96 Dessauer, H. C. \& Cole, C. J. Diversity between and within nominal forms of unisexual teiid lizards. Evolution and ecology of unisexual vertebrates. New York State Museum Bulletin 466, 49-71 (1989).

97 Moritz, C. et al. The material ancestry and approximate age of parthenogenetic species of Caucasian rock lizards (Lacerta: Lacertidae). Genetica 87, 53-62, doi:10.1007/bf00128773 (1992).

98 Uzzell, T. \& Darevsky, I. S. Biochemical evidence for the hybrid origin of the parthenogenetic species of the Lacerta saxicola complex (Sauria: Lacertidae), with a discussion of some ecological and evolutionary implications. Copeia, 204-222 (1975).

99 Reeder, T. W., Cole, C. J. \& Dessauer, H. C. Phylogenetic relationships of whiptail lizards of the genus Cnemidophorus (Squamata: Teiidae): a test of monophyly, reevaluation of karyotypic evolution, and review of hybrid origins. American Museum Novitates, 1-61 (2002).

100 Tucker, D. B. et al. Methodological congruence in phylogenomic analyses with morphological support for teiid lizards (Sauria: Teiidae). Molecular phylogenetics and evolution 103, 75-84 (2016).

101 Moritz, C. et al. in Evolution and Ecology of Unisexual Vertebrates Vol. 466 (eds Robert M Dawley \& James P Bogart) 87-112 (New York State Museum Bulletin, 1989).

102 Good, D. \& Wright, J. Allozymes and the hybrid origin of the parthenogenetic lizardCnemidophorus exsanguis. Experientia 40, 1012-1014 (1984).

103 Lutes, A. A., Baumann, D. P., Neaves, W. B. \& Baumann, P. Laboratory synthesis of an independently reproducing vertebrate species. Proceedings of the National Academy of Sciences 108, 9910-9915 (2011).

104 Scharnweber, K., Plath, M., Winemiller, K. \& Tobler, M. Dietary niche overlap in sympatric asexual and sexual livebearing fishes Poecilia spp. Journal of Fish Biology 79, 1760-1773 (2011).

105 Tobler, M. \& Schlupp, I. Parasites in sexual and asexual mollies (Poecilia, Poeciliidae, Teleostei): a case for the Red Queen? Biology Letters 1, 166-168 (2005).

106 Schlupp, I., Marler, C. \& Ryan, M. J. Benefit to male sailfin mollies of mating with heterospecific females. Science 263, 373-374 (1994).

107 Vrijenhoek, R. C. Animal clones and diversity. Bioscience 48, 617-628 (1998).

108 Quattro, J., Avise, J. \& Vrijenhoek, R. Molecular evidence for multiple origins of hybridogenetic fish clones (Poeciliidae: Poeciliopsis). Genetics 127, 391-398 (1991).

109 Vrijenhoek, R. in Population Biology and Evolution 217-231 (Springer, 1984).

110 Gray, M. M. \& Weeks, S. C. Niche breadth in clonal and sexual fish (Poeciliopsis): a test of the frozen niche variation model. Canadian Journal of Fisheries and Aquatic Sciences 58, 1313-1318 (2001).

111 Semlitsch, R. D., Hotz, H. \& Guex, G. D. Competition among tadpoles of coexisting hemiclones of hybridogenetic Rana esculenta: support for the frozen niche variation model. Evolution 51, 1249-1261 (1997).

\section{Competing interests}

We declare no competing interests. 
779 Contributions

$780 \mathrm{KLL}, \mathrm{MW}$ and JK conceived the idea for the manuscript. KLL wrote the initital draft. All authors

781 substantially contributed to revisions and editing of manuscript.

782

783 Correspondence

784 Correspondence should be directed to KLL, laskowski@igb-berlin.de

785

\section{Acknowledgements}

787 We would like to thank Manfred Schartl and Ingo Schlupp for constructive conversations. This work 788 was supported in part by the Deutsche Forschungsgemeinschaft (Grant LA 3778/1-1 to KLL; grant 789 BI 1828/2-1 to DB), and the Alexander von Humboldt Foundation (Postdoctoral Fellowship to CD). 790 